\title{
Risk assessment of the step-by-step return-to-work policy in Beijing following the COVID-19 epidemic peak
}

\author{
Wen-bin Zhang ${ }^{1,2} \cdot$ Yong Ge $^{1,2} \cdot$ Mengxiao Liu ${ }^{1,2} \cdot$ Peter M. Atkinson ${ }^{1,3} \cdot$ Jinfeng Wang ${ }^{1,2} \cdot$ \\ Xining Zhang ${ }^{1,2} \cdot$ Zhaoxing Tian $^{4}$
}

Accepted: 30 October 2020/Published online: 13 November 2020

(c) Springer-Verlag GmbH Germany, part of Springer Nature 2020

\begin{abstract}
Novel coronavirus (COVID-19) is a new strain of coronavirus first identified in Wuhan, China. As the virus spread worldwide causing a global pandemic, China reduced transmission at considerable social and economic cost. Postlockdown, resuming work safely, that is, while avoiding a second epidemic outbreak, is a major challenge. Exacerbating this challenge, Beijing hosts many residents and workers with origins elsewhere, making it a relatively high-risk region in which to resume work. Nevertheless, the step-by-step approach taken by Beijing appears to have been effective so far. To learn from the epidemic progression and return-to-work measures undertaken in Beijing, and to inform efforts to avoid a second outbreak of COVID-19, we simulated the epidemiological progression of COVID-19 in Beijing under the real scenario of multiple stages of resuming work. A new epidemic transmission model was developed from a modified SEIR model for SARS, tailored to the situation of Beijing and fitted using multi-source data. Because of strong spatial heterogeneity amongst the population, socio-economic factors and medical capacity of Beijing, the risk assessment was undertaken spatiotemporally with respect to each district of Beijing. The epidemic simulation confirmed that the policy of resuming work step-by step, as implemented in Beijing, was sufficient to avoid a recurrence of the epidemic. Moreover, because of the structure of the model, the simulation provided insights into the specific factors at play at different stages of resuming work, allowing district-specific recommendations to be made with respect to monitoring at different stages of resuming work. As such, this research provides important lessons for other cities and regions dealing with outbreaks of COVID-19 and implementing return-to-work policies.
\end{abstract}

Keywords COVID-19 $\cdot$ Resuming work $\cdot$ Socio-economic activities $\cdot$ Heterogeneity $\cdot$ Beijing

Yong Ge

gey@1reis.ac.cn

$1 \quad$ State Key Laboratory of Resources and Environmental Information Systems, Institute of Geographic Sciences and Natural Resources Research, Chinese Academy of Sciences, Beijing 100101, China

2 University of Chinese Academy of Sciences, Beijing 100049, China

3 Lancaster Environment Center, Faculty of Science and Technology, Lancaster University, Lancaster LA1 4YR, UK

4 Emergency Department of Peking, University International Hospital, Beijing, China

\section{Introduction}

Novel coronavirus (COVID-19) is a new strain of coronavirus with a high transmission ability that has spread widely since January 2020 (North China Morning Post 2020; Zhu et al. 2020; Li et al. 2020; Sujath et al. 2020). It is recognized as the most serious respiratory virus since the 1918 H1N1 influenza pandemic in terms of public health threat (Dorigatti et al. 2020). Since 31 December 2019, and as of 11 August 2020, 20,075,600 cases of COVID-19 (in accordance with the applied case definitions in the affected countries) were reported, including 736,372 deaths (European Centre for Disease Prevention and Control 2020). With the virus has a foothold on every continent, the pandemic threat has already been realized (World Health Organization 2020a; Chen et al. 2020), and many countries 
have published serval pandemic-prevention measures thereafter in response, such as lockdown. However, in the post-pandemic world, the reopening of society is in strong need, and the corresponding risk assessment is necessary for megacities to carefully lift the issued measures avoiding the ongoing outbreaks of COVID-19.

As COVID-19 has spread worldwide, China has eased transmission of the virus at considerable social and economic cost. We focus on Beijing, China because it provides an informative case showing progress from pandemic outbreak to government curbs on the pandemic, and further to the resumption of work. In fact, Beijing started to resume work on 10 February 2020 (Xinhua net 2020a), and production levels were back to $88.9 \%$ as early as 15 March 2020 (Xinhua net 2020b). As one of the largest cities in China, Beijing has 21.5 million residents, of which 7.6 million are in-migrants (domestic migrants) (Beijing Municipal Bureau Statistics 2019). This flux of migrant workers makes Beijing a high-risk region in terms of resuming work. In addition, because of the large distances between workplaces and residences in the city and the possibility of asymptomatic transmission of the virus, the ubiquity of commuting raises transmission possibilities in Beijing (Chinazzi et al. 2020; Chen et al. 2020). To begin economic recovery while maintaining a low risk of a second outbreak of COVID-19, step-by-step measures to return to work were taken by the Beijing government. The resumption of work in Beijing could bring significant risks if not well controlled. Several existing studies showed that influenza spread has an intrinsic spatio-temporal behavior, and the diffusion of infected cases in a given area is likely to be uneven and determined by the distribution of susceptible hosts (Qian et al. 2009; Moustakas 2017; Moss et al. 2019; Amorós et al. 2020). For example, individuals in schools have many more contacts with other people than those who stay at home most of the time, so regions with more schools are at higher risk. In addition, mode of employment and the scale of one's workplace also have a great impact on the probability of infection (Aschwanden 2004). Controlling for the number of susceptible hosts, $k$ is larger for companies operating within more confined spaces than, for example, hotels and some public places, such as parks.

To analyze the goal of resuming social and economic operations while avoiding a re-outbreak of COVID-19, we conducted a simulation analysis of the risk of pandemic outbreak for Beijing at different stages of resuming work. The basic transmission model we employed is the modified SEIR model proposed by Lipsitch et al. (2003), revised according to the circumstances of the pandemic in Beijing represented using multi-source data; that is, population (residents and in-migrants), socio-economic factors and medical capacity. Although the economy is not the focus of pandemic models, it is appropriate to consider some economic impacts (Enserink and Kupferschmidt 2020), since transmitted infectious diseases can cause extensive morbidity, mortality and economic burden (Choi et al. 2008; Christakos et al. 2017). Heterogeneity exists across the districts of Beijing in the population distribution and local socio-economic factors (Song et al. 2019; Brunton et al. 2017). At different stages of resuming work, the business functions in operation vary (Beijing Youth Daily 2020), leading to different situations in different districts (i.e. different outbreak risk). Districts with large populations will not necessarily become high-risk regions, because the majority of residents will stay home for much of time if the district has few open workplaces. Thus, it is unreasonable to employ a single simulation model in developing pandemic-prevention measures for all districts (Yin et al. 2019; Chien and Chen 2020). From this perspective, we study the risk of resuming work for each district based on the spatially heterogeneous characteristics of the population, socio-economic factors and medical capacity. In particular, two parameters of the transmission model are evaluated locally: the daily contact number per capita and the mean daily rate at which infectious cases (who are not in quarantine) are detected and isolated. Each is evaluated using district-specific socio-economic factors and the medical capacity associated with the local population. Then, we produce a spatial-temporal risk assessment based on the district-specific parameters and propose relevant pandemicprevention measures. The overall aim is to provide valuable insights for other cities or regions anticipating the journey from pandemic outbreak to transmission prevention to resumption of socio-economic activities.

\section{Methodology and materials}

\subsection{Revised SEIR model}

COVID-19 is a disease caused by the virus severe acute respiratory syndrome coronavirus 2 (SARS-CoV-2) (Langousis and Carsteanu 2020; Sivakumar 2020) which is genetically related to the coronavirus responsible for the SARS outbreak of 2003 (World Health Organization 2020b). To model the epidemiological progression of COVID-19, the transmission model for SARS (Lipsitch et al. 2003) was adapted. The transmission model for SARS is a modification of the standard SEIR model (Anderson and May 1991). The standard SEIR model tracks susceptible, exposed (infected but not yet infectious), infectious and recovered individuals in the compartments S, E, I and R, respectively, whereas the Lipsitch transmission model further incorporates quarantine measures into the SEIR model. Specifically, susceptible individuals 
are divided into 'susceptible' and 'susceptible but isolated' (compartments $S$ and $S_{Q}$ ), exposed individuals are divided into 'exposed' and 'exposed but isolated' (compartments $E$ and $E_{Q}$ ) and infectious individuals are divided into 'those who have not been isolated' $\left(I_{U}\right)$, and 'those who have been hospitalized' $\left(I_{D}\right)$. Based on the evidence for indirect transmission resulting from transmission by asymptomatic infected persons and pre-symptomatic transmission (Cai et al. 2020; Tong et al. 2020; Bai et al. 2020; Nishiura et al. 2020; Rothe et al. 2020), we further modified the model by assuming that a fraction $p$ of all infectious persons are asymptomatic $(1-p$ of all infectious persons are symptomatic), that a proportion $b_{a}$ of people who make contact with an asymptomatic person are infected, and a proportion $b_{s}$ of people who make contact with a symptomatic person are infected. In this situation, the probability of a susceptible person becoming infected by contacting an infectious person is $b_{s}(1-p)+b_{a} p$, and the probability of a susceptible who makes contact not becoming infected is $\left(1-b_{s}\right)(1-p)+\left(1-b_{a}\right) p$. For simplicity, we use the notation $b$ to represent $b_{s}(1-p)+b_{a} p$ and $1-b$ to represent $\left(1-b_{s}\right)(1-p)+\left(1-b_{a}\right) p$. In addition, we model the situation in which Beijing faces the return of considerable numbers of people from elsewhere in the country; thus, two parameters $\mathrm{S}_{B}^{t}$ and $\mathrm{E}_{B}^{t}$ are incorporated into the model, representing imported susceptible people and imported exposed people, respectively. That is,

$$
\begin{aligned}
& \mathrm{d} S / \mathrm{d} t=S_{B}^{t}-(b+(1-b) q) k_{t} I_{U} S / N 0+r_{Q} S_{Q} \\
& \mathrm{~d} S_{Q} / \mathrm{d} t=(1-b) k_{t} I_{U} q S / N 0-r_{Q} S_{Q} \\
& \mathrm{~d} E / \mathrm{d} t=(1-q) E_{B}^{t}+b(1-q) k_{t} I_{U} S / N 0-r E \\
& \mathrm{~d} E_{Q} / \mathrm{d} t=q E_{B}^{t}+b q k_{t} I_{U} S / N 0-r E_{Q} \\
& \mathrm{~d} I_{U} / \mathrm{d} t=r E-(v+m+w) I_{U} \\
& \mathrm{~d} I_{D} / \mathrm{d} t=r E_{Q}+w I_{U}-(v+m) I_{D} \\
& \mathrm{~d} R / \mathrm{d} t=v\left(I_{U}+I_{D}\right) \\
& \mathrm{d}(\text { dead }) / \mathrm{d} t=m\left(I_{U}+I_{D}\right)
\end{aligned}
$$

It should be noted that the superscript $t$ in $\mathrm{S}_{B}^{t}$ and $\mathrm{E}_{B}^{t}$ indicates the stage of resuming work. For different stages of resuming work, there will be different populations of imported migrants. In this study, the resumption rate is reflected by the corresponding proportion of imported migrants. Moreover, during the specific stage of resuming work, the daily contact number per capita is determined by the corresponding reopened socio-economic factors, denoted by $k_{t}$. That is the parameter $k_{t}$ in the revised SEIR model varies with the resumption rate, because reopened businesses at different stages of resumption have different abilities to attract people. At the initial stage of resuming work, there were only essential services reopened. To reflect the ability of these reopened essential services attracting people, we used the density of POI regarding the essential services to characterize the value of the parameter $k_{t}$ for this initial stage. The mean daily rate at which infectious cases are detected and isolated is determined by the medical capacity which is denoted by $w$. This parameter $w$ is constant because medical resources were at full operation in the initial stages of resumption. The other parameters in Eq. (1) are independent of resumption rate, and are also considered constant in this study. Figure 1 illustrate the mechanism for our transmission model.

The classic SEIR model is accepted widely as a basic model to describe the properties of COVID-19 transmission. Hou et al. (2020) and He et al. (2020a) employed a mixed SEIR compartmental model assuming that susceptible individuals contacting an exposed individual would probably become infected. Yang et al. (2020) modified the original SEIR model, introducing move-in and move-out parameters, because the initial outbreak of COVID-19 in China occurred during the Spring Festival. At that time, hundreds of millions of people moved between the provinces of China. Despite these modifications some properties of COVID-19 transmission, particularly pandemicprevention measures, were not considered. Therefore, here, a quarantined component is added into the classic SEIR model as a fifth element in addition to the four elements: $S$ (susceptible), E (exposed), I (infectious) and R (recovered) (Lopez and Rodó 2020). Furthermore, He et al. (2002b) added another element, hospitalized, representing the part of the infectious population that cannot contact other people. Infectious individuals still active in society and potentially spreading the virus should be distinguished from hospitalized infectious individuals. Wei et al. (2020) considered a more detailed scenario, where asymptomatic infected persons are introduced. In contrast, our model incorporates the above considerations into the classic SEIR model with some simplifications providing a comprehensive characterization of the properties of COVID-19 transmission in Beijing.

\subsection{Estimating the reproductive number}

In the absence of quarantine, the reproductive number for this model is given by $R=b k D$, where $D$ is the mean duration of infectiousness, $D=1 /(v+m+w)$. The effect of quarantining a fraction $\mathrm{q}$ of contacts of infectious persons is to multiply this expression by $(1-q)$ (Lipsitch et al. 2003). On the other hand, the reproductive number can be calculated deterministically by the formula $R=1+v \lambda+f(1-f)(v \lambda)^{2}$, where $f$ is the ratio of the infectious period to the serial interval. $v$ is the sum of the mean infectious and mean latent periods, and $\lambda$ is the exponential growth rate of the cumulative number of cases in the pandemic (Lipsitch et al. 2003). 
Fig. 1 Schematic representation of the revised transmission model

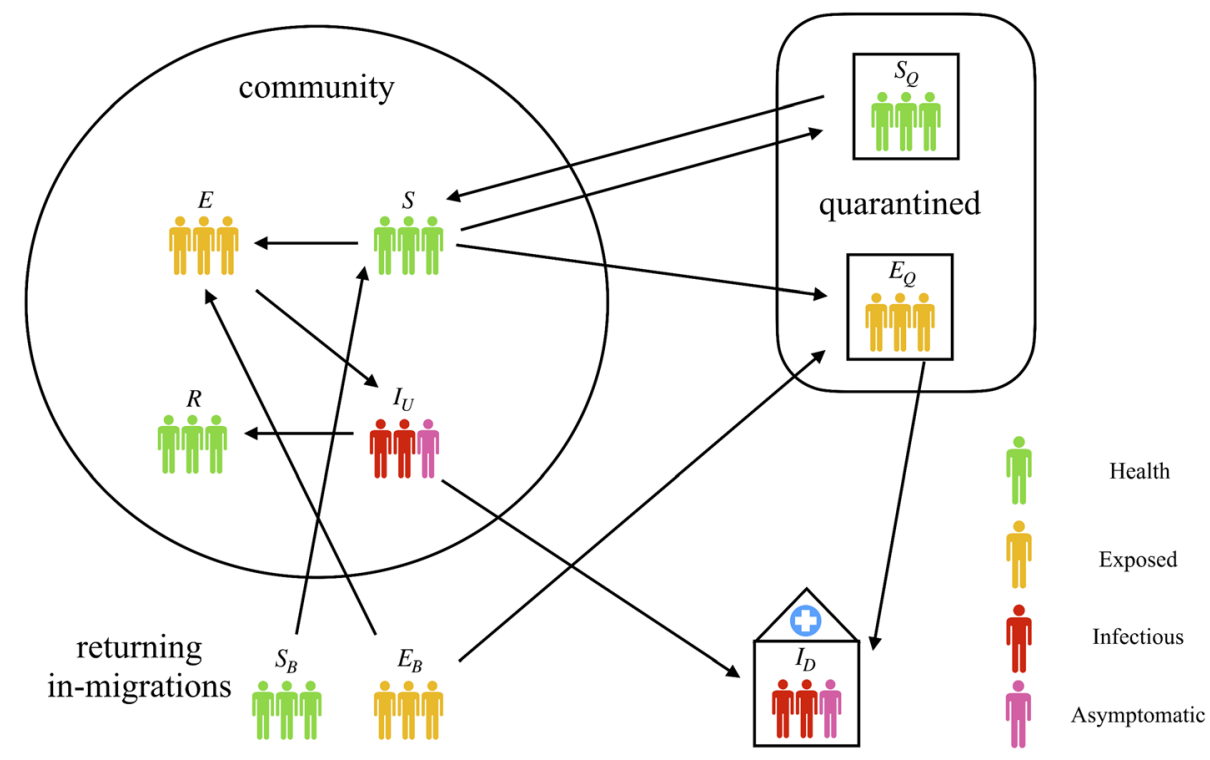

\subsection{Data collection and preprocessing}

Pandemic data for Beijing were collected from the website of the Beijing Municipal Health Commission (http://wjw. beijing.gov.cn/xwzx_20031/wnxw/) including daily confirmed cases, daily recovered cases and daily death cases for Beijing Municipality, as well as the total confirmed cases for each district of Beijing Municipality. The Beijing pandemic was first reported on 20 January 2020. To initialize the model, we assume that there were only exposed individuals at that time as a result of passenger inflow from Wuhan direct to Beijing. After the travel ban from Wuhan, the growth of the pandemic in Beijing can be viewed as based on internal progression within Beijing without further imported cases (Tian et al. 2020).

With Beijing reopened, socio-economic factors and medical capacity within the different districts of Beijing play important roles in the evolution of the epidemic. To better describe the evolution of the epidemic in Beijing, we collected multi-source data with which to fit the revised SEIR model. Socio-economic factors and medical capacity are described by the densities (pcs per square kilometer) of socio-economic activity places (SEAPs) and medical services, respectively, within each district of Beijing. The density of SEAPs for each district is measured by the density of POIs (points of interest) collected from the Gaode Map API (https://lbs.amap.com/api/webservice/ guide/api/search) including 10 major categories: Accommodation Services, Governmental Organization, Financial and Insurance Services, Commercial Business, Enterprises, Shopping, Food and Beverages, Transportation Services, Science/Culture and Education Services, and Sports and Recreation. Medical Services per se is a major category of the POI data. Thus, the corresponding densities were used directly to describe the medical capacity for each district.

With respect to SEAPs, each major category consists of related granular categories, each of which has different population flows. Therefore, we assigned weights to the granular categories to calculate the density of each major category, specifically as the weighted average of the densities of the corresponding granular categories (see Table 5 in "Appendix"). For example, the major category Accommodation Services includes two granular categories, Hotel and Hostel. Because Hotel had a smaller population flow than Hostel, the weights of Hotel and Hostel were set as 0.4 and 0.6 , respectively. It should be noted that the weights here represent the relative, rather than the absolute, magnitude. The densities of the other nine major categories were obtained in the same way. Next, the density of SEAPs was obtained by the weighted average of the densities of the 10 major categories, wherein the weights of the major categories were pre-defined according to their relative population flows also (see Table 5 in "Appendix"). Medical capacity was quantified by the density of medical services consisting of four granular categories in a similar way, but with the weights for the four granular categories of medical services pre-defined based on their theme relevance to the epidemic (see Table 5 in "Appendix"). For example, the largest weight was assigned to the granular category, Special Hospital, because one of the themes of it is infectious disease. The POI dataset was generated in 2017, while the acquisition time was March 2020. Population numbers of both residents and in-migrants for each district of Beijing were collected from the Beijing Statistical Yearbook in 2019 (Beijing Municipal Bureau Statistics 2019). 
We employed non-linear least squares for parameter estimation by minimizing the distance between the predicted $I_{D}, R$, dead and corresponding observed numbers from 20 January 2020 to 20 March 2020. With respect to the parameters, the duration of quarantine, the average time of progression from latent infection to infectious, the proportion of asymptomatic cases and the per capita death rate were determined according to relevant reports (World Health Organization 2020c; Lauer et al. 2020; Mizumoto et al. 2020; Xia et al. 2020). The imported exposed population, the daily number of contacts per capita, the fraction of all persons contacted by an infectious person who are successfully quarantined, the per capita recovery rate, the transmission probability and the mean daily rate at which infectious cases are detected and isolated are estimated and given in Table 1. For each district of Beijing, we assumed that all parameters were the same as for the greater Beijing Municipality, except the daily contact number $k$, detection rate $w$ and quarantine fraction $q$. The first two parameters are considered to reflect the spatial heterogeneity of people's behavior and the medical capacity of each district. Districts with more companies and schools, for example, tend to have larger daily contact numbers. To reduce the uncertainty of the model, we employed socio-economic factors and medical capacity in the evaluation of the parameters $k$ and $w$, respectively. The socio-economic factors and medical capacity were determined by the POI data. That is the parameters $k$ and $w$ were determined by the densities of SEAPs and medical services regarding the whole Beijing Municipality. Then, the quarantine fraction $q$ of each district was estimated based on local pandemic data with a fixed daily contact number $k$ and detection rate $w$. Under the circumstances, we set the local resident population as the susceptible population for each district.
For simplicity, the districts of Beijing Municipality are named as follows: DC (Dongcheng District); XC (Xicheng District); CY (Chaoyang District); FT (Fengtai District); SJS (Shijingshan District); HD (Haidian District); MTG (Mentougou District); FS (Fangshan District); TZ (Tongzhou District); SY (Shunyi District); CP (Changping District); DX (Daxing District); HR (Huairou District); PG (Pinggu District); MY (Miyun District); YQ (Yanqing District).

\section{Results}

\subsection{Chronology of resumption of socio-economic activities}

To slow the pandemic, migrant residents returned to Beijing batch-by-batch in terms of their profession. Based on the timeline of resuming work (see Fig. 2), we simplify the situation into six scenarios with resumption rates from 50 to $100 \%$ :

Stage 1. Resumption of work at $50 \%$ by 20 February 2020, including Accommodation Services, Governmental Organization, Financial and Insurance Services, Commercial Business, and Enterprises;

Stage 2. Resumption of work at $60 \%$ by 1 March 2020. In addition to the five types of workplace mentioned above, Shopping was added, reflecting reports that around $90 \%$ of shops and markets reopened on 23 February;

Stage 3. Resumption of work at $70 \%$ by 10 March 2020. In this scenario, we assume no extra categories of business resume;

Table 1 Initial conditions and parameters for the Beijing pandemic

\begin{tabular}{llll}
\hline Symbol & Parameter & Value $(\boldsymbol{\alpha}=0.05)$ & Source \\
\hline$S_{Q}$ & Susceptible but quarantined & 0 & Assumption \\
$E$ & Exposed-infected but not yet infectious & 70 & Assumption \\
$E_{Q}$ & Exposed but quarantined & 0 & Assumption \\
$I_{U}$ & Infectious who are not yet detected and isolated & 0 & Assumption \\
$1 / r_{q}$ & Duration of quarantine & 14 & Reference \\
$1 / r$ & Average time of progression from latent infection to infectious & 5 & Reference \\
$m$ & The per capita death rate & 0.0009 & Reference \\
$k$ & The daily number of contacts per capita & 5.4668 & POI \\
$w$ & The mean daily rate at which infectious cases are detected and isolated & 0.8579 & POI \\
$q$ & The fraction of all person contacted by an infectious person are successfully quarantined & $0.99 \pm 0.0847$ & Estimated \\
$v$ & The per capita recovery rate & $0.032 \pm 0.0029$ & Estimated \\
$b$ & The probability of transmission per contact between a susceptible and an infectious person & $0.6 \pm 0.1626$ & Estimated \\
\hline
\end{tabular}




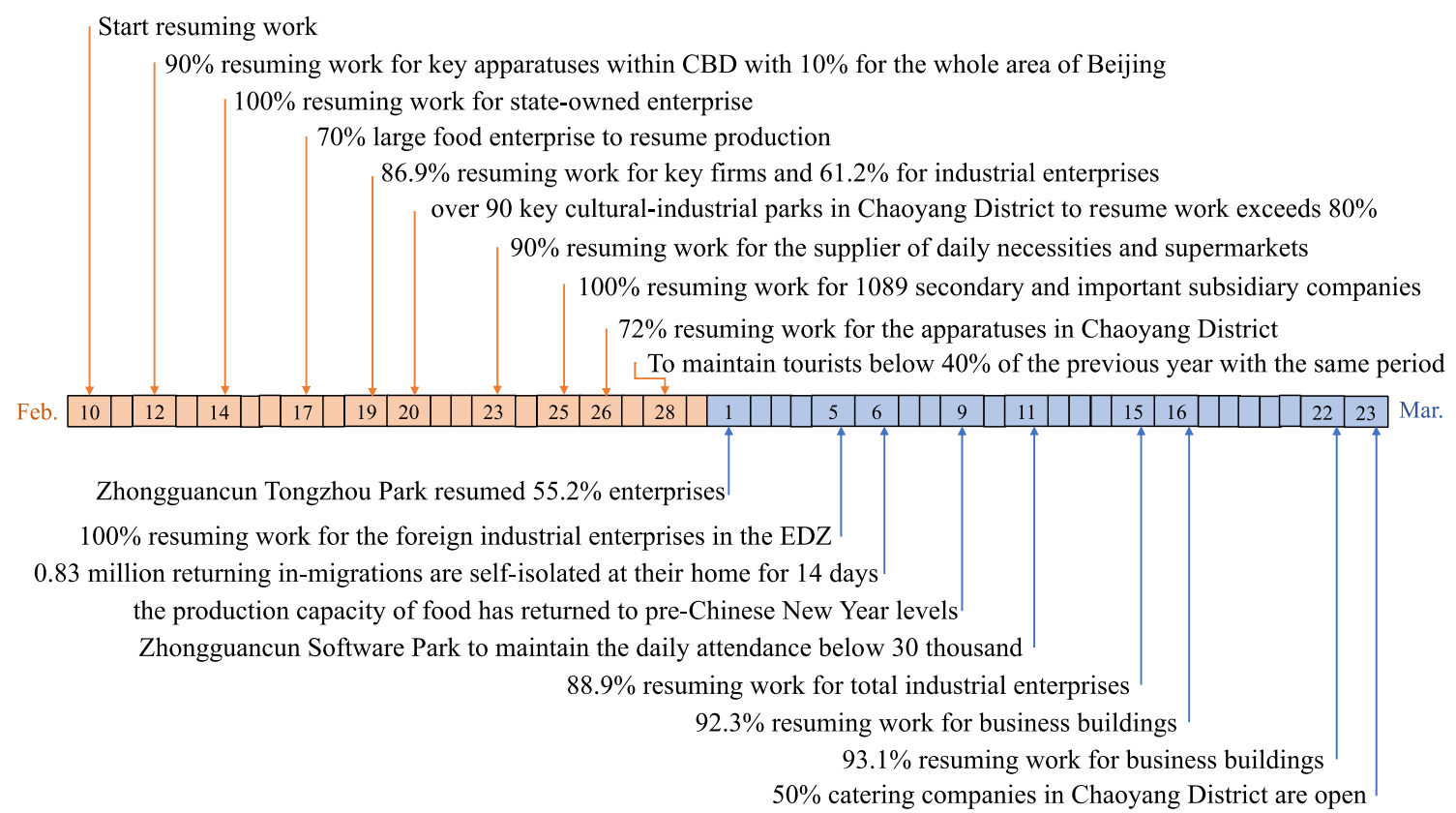

Fig. 2 The timeline for resuming work in Beijing. EDZ (Economic Development Zone)

Stage 4. Resumption of work at $80 \%$ by 20 March 2020. Food and Beverages were added to the resuming businesses, since it is reported that around half of the restaurants in the Chaoyang District reopened by 23 March 2020;

Stage 5. Resumption of work at $90 \%$ by 30 March 2020. Transportation Services were added to the resuming businesses;

Stage 6. Resumption of work at $100 \%$ by 10 April 2020. In this scenario, we assume the resumption of all business categories, where Science/ Culture and Education Services and Sports and Recreation are the final two categories reopened. These two public services are more confined to places with high population mobility.

At different stages of resuming work, the factors contributing to the contact number are selected based on the process in Fig. 2, leading to a heterogeneous situation (see Table 2). At a certain stage of resuming work, the parameter $k$ is the weighted average of the densities of the selected categories of POI data within each district. The baseline represents the circumstance under the Spring Festival, when local residents stay at home with only three major categories of POI opened (i.e. Governmental Organization, Commercial Business, and Accommodation Services). At this stage, the contact number in each district is contributed by the corresponding density of open business functions and housing units. For example, within Dongcheng District, the value of parameter $k$ is the weighted average of the densities of Governmental organization, Commercial Business, and Accommodation Services, where the weights are pre-defined (see Table 5 in "Appendix"). Then, for each stage of resuming work, the parameter $k$ for each district is calculated in the same way with corresponding reopened major categories. The parameter $w$ represents the medical capacity to characterize the mean daily rate at which infectious cases are detected and isolated. In this research, medical capacity was captured by the density of Medical Services which can also be estimated from the POI data. It should be noted that Medical Services have been operating at full capacity through the period of this study. Therefore, the parameter $w$ is a constant amid resuming work. As in Sect. 2.3, the parameter $w$ for each district equals to the density of Medical Services within each district.

\subsection{The impact of resuming work on virus transmission}

Under each scenario, the estimated total confirmed cases from 20 February to 10 April 2020 are distributed unevenly due to the heterogeneity of the multi-source data used and the step-by-step return-to-work policies. After resuming work, the pandemic increases for a short period in most districts, with the central region showing the most significant increase because of the high density of enterprises and transportation links.

To characterize the real situation more closely, we introduced more parameters to the model. The model fit for the Beijing pandemic is satisfactory (see Fig. 3a), although 
Table 2 Two district-specific SEIR model parameters at different stages of resuming work

\begin{tabular}{|c|c|c|c|c|c|c|c|c|}
\hline \multirow[t]{2}{*}{ District } & \multicolumn{7}{|l|}{$k$} & \multirow[t]{2}{*}{$w$} \\
\hline & Baseline & $50 \%$ & $60 \%$ & $70 \%$ & $80 \%$ & $90 \%$ & $100 \%$ & \\
\hline DC & 6.814 & 17.500 & 18.485 & 18.485 & 22.611 & 22.625 & 25.294 & 0.694 \\
\hline $\mathrm{XC}$ & 6.166 & 14.355 & 15.431 & 15.431 & 18.929 & 18.939 & 21.503 & 0.702 \\
\hline CY & 1.204 & 4.612 & 4.897 & 4.897 & 6.357 & 6.361 & 7.264 & 0.130 \\
\hline FT & 0.982 & 3.094 & 3.369 & 3.369 & 4.295 & 4.300 & 4.853 & 0.115 \\
\hline SJS & 1.170 & 3.000 & 3.180 & 3.180 & 3.908 & 3.912 & 4.625 & 0.123 \\
\hline HD & 1.135 & 3.887 & 4.061 & 4.061 & 4.982 & 4.985 & 6.128 & 0.131 \\
\hline MTG & 0.052 & 0.080 & 0.083 & 0.083 & 0.100 & 0.100 & 0.117 & 0.003 \\
\hline FS & 0.073 & 0.166 & 0.180 & 0.180 & 0.229 & 0.230 & 0.276 & 0.012 \\
\hline $\mathrm{TZ}$ & 0.213 & 0.744 & 0.791 & 0.791 & 0.999 & 1.000 & 1.163 & 0.020 \\
\hline SY & 0.174 & 0.461 & 0.493 & 0.493 & 0.612 & 0.613 & 0.696 & 0.021 \\
\hline $\mathrm{CP}$ & 0.172 & 0.485 & 0.525 & 0.525 & 0.711 & 0.712 & 0.881 & 0.025 \\
\hline DX & 0.200 & 0.799 & 0.841 & 0.841 & 1.043 & 1.043 & 1.171 & 0.024 \\
\hline HR & 0.057 & 0.105 & 0.111 & 0.111 & 0.134 & 0.134 & 0.156 & 0.006 \\
\hline PG & 0.093 & 0.185 & 0.197 & 0.197 & 0.229 & 0.230 & 0.277 & 0.009 \\
\hline MY & 0.035 & 0.061 & 0.065 & 0.065 & 0.077 & 0.088 & 0.100 & 0.004 \\
\hline YQ & 0.023 & 0.033 & 0.035 & 0.035 & 0.044 & 0.050 & 0.058 & 0.002 \\
\hline
\end{tabular}
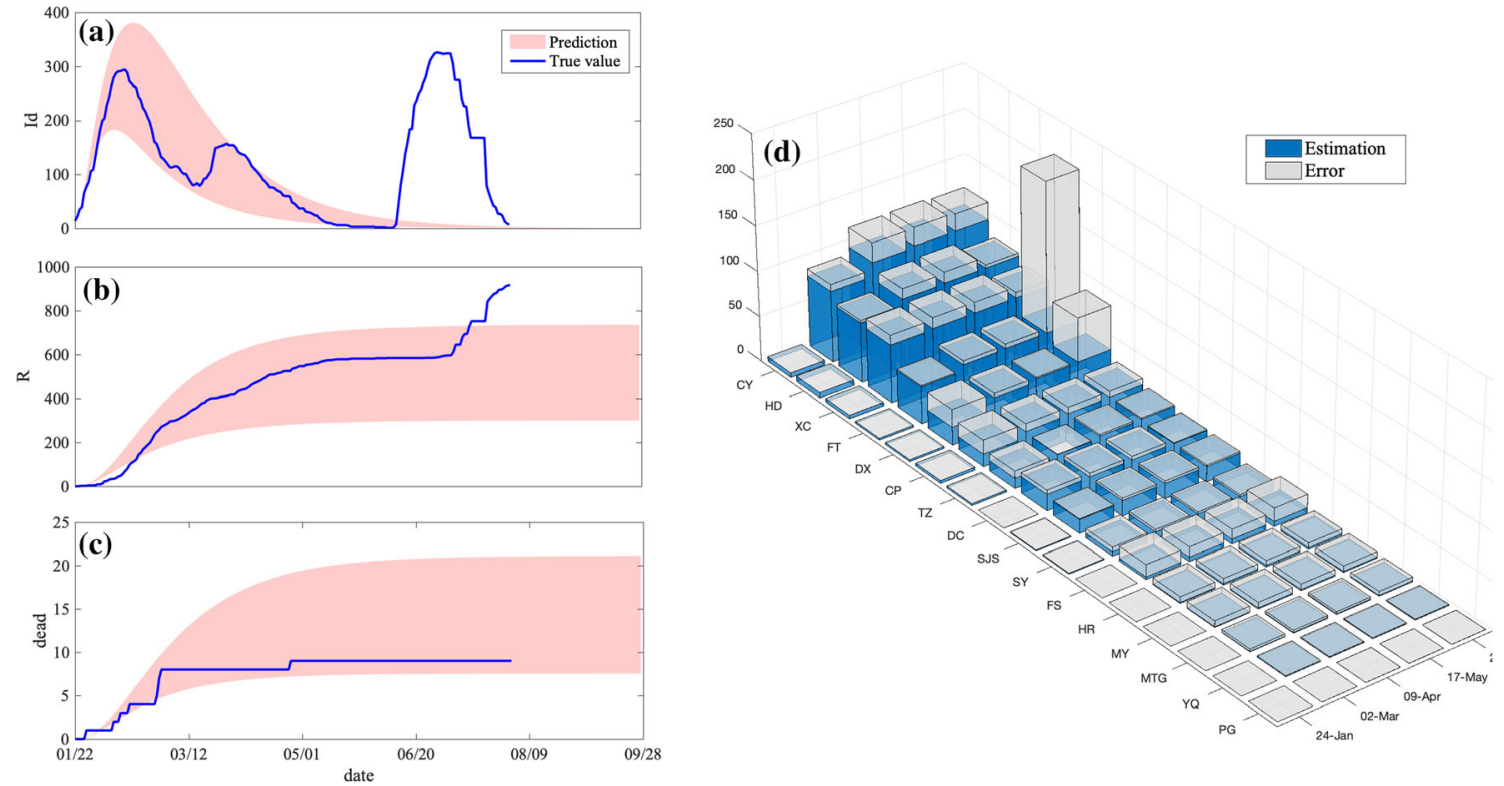

Fig. 3 a-c Comparison between the fitted model and observed data with respect to Beijing. Id represents infectious individuals who are detected and isolated, and $\mathrm{R}$ represents recovered individuals.

it should be noted that the uncertainty for some parameters is large because imported cases are not considered by the modified SEIR model. The simulated total number of confirmed cases revealed Chaoyang District to be the highest risk region, while Fengtai District produced the most cases up to 1 Aug. 2020 (see Fig. 3b). Besides, the large error associated with Fengtai District in 24 Jun. is also caused by imported cases. In fact, the pandemic in Beijing appears to have a short duration. In early March d Validation of the estimated total number of confirmed cases with respect to each district in Beijing. The error is calculated into absolute value to represent the size of it

2020, the total confirmed cases within each district gradually becomes stable, and the new confirmed cases thereafter are all related to imported cases.

Different from the total number of confirmed cases, the number of active cases is required to assess the current risk of COVID-19. Active cases refer to undetected infectious individuals, $I_{u}$, who can still come into contact with susceptible individuals, such that these susceptible people may become infected. The total number of confirmed cases 
consists of existing confirmed, recovered and dead cases, where clearly the latter two bring no risk to the susceptible population. The simulated evolution of active cases of COVID-19 for each district of Beijing under different stages of return-to-work is demonstrated in Fig. 4a-d. Different from a simple cumulative process of total confirmed cases, confirmed active cases behave more dynamically within the process of resuming work. For example, the number of active cases in Huairou District increases at the start of resuming work, and gradually decreases in the post-resuming work stage. At the different stages of resuming work, the risk comes from different resuming business categories, influencing the spatial distribution of $k$ and the infectious population. Enterprises and factories reopened first, as they were viewed as imperative for the domestic economy, followed by markets, the catering industry and public transportation. About $60 \%$ of economic operations resumed by 1 March 2020, such that attention should be paid to towns with the most densely located shopping services. Work resumed by $80 \%$ by 20 March, such that towns with the most densely located food and beverage operations should also be monitored. When transportation returned from lockdown to full capacity, towns with more transportation services should be included

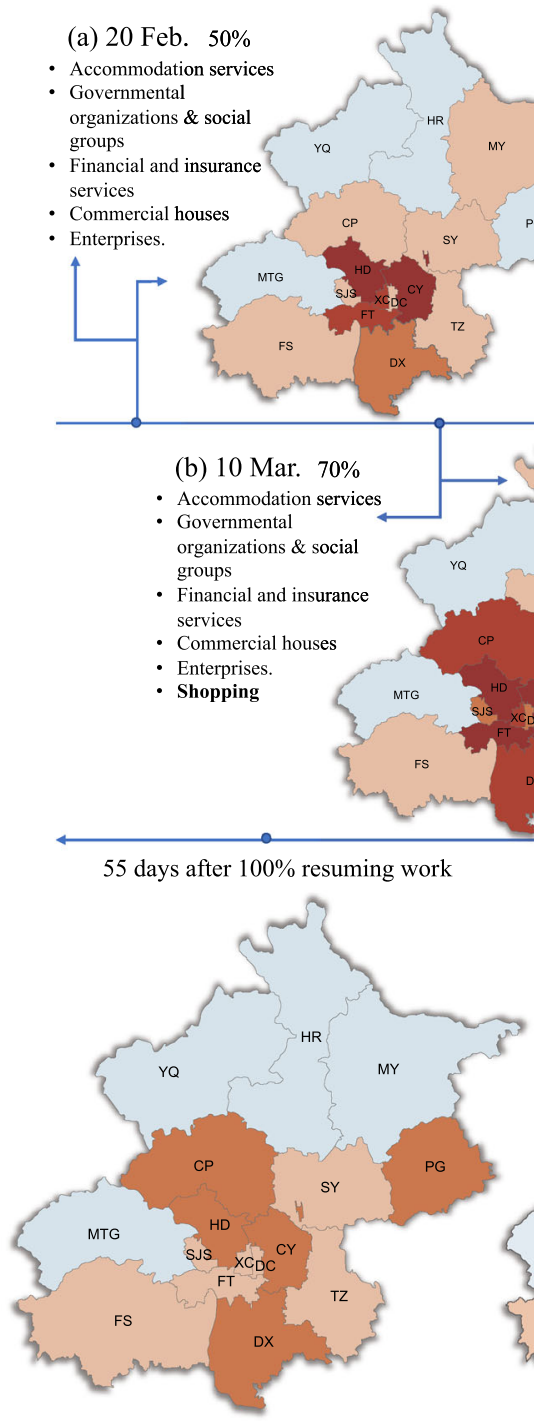

(g) 30 May (c) 30 Mar. $90 \%$

- Accommodation services

- Governmental

organizations \& social

groups

- Financial and insurance

services

- Commercial houses

- Enterprises.

- Shopping

- Food and beverages

Transportation services

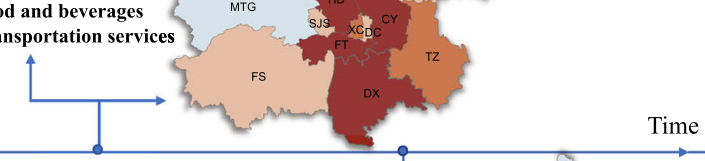

(d) 10 Apr. $100 \%$

- Accommodation services

- Governmental

organizations \& social

groups

- Financial and insurance

services

- Commercial houses

- Enterprises.

- Shopping

- Food and beverages

Transportation services

- Science/culture \&

education services

Sports \& recreation

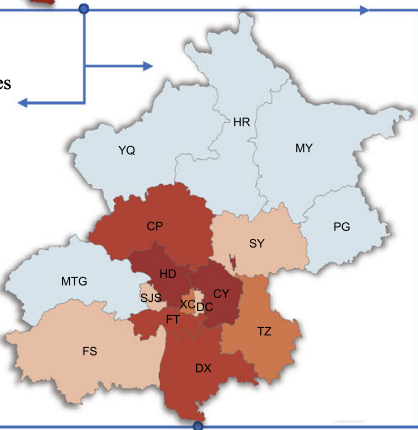

35 days after $100 \%$ resuming work

10 days after $100 \%$ resuming work

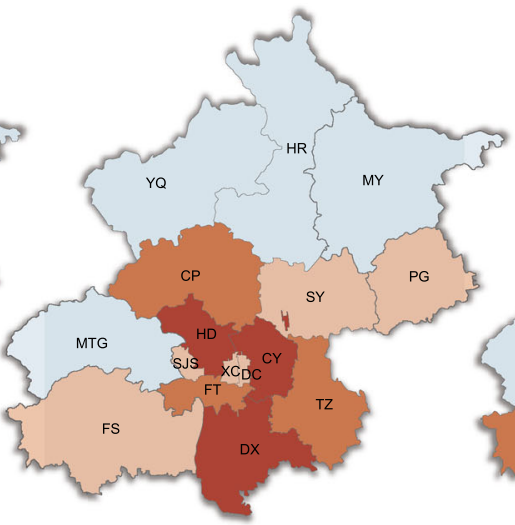

(f) 15 May (e) 20 Apr.

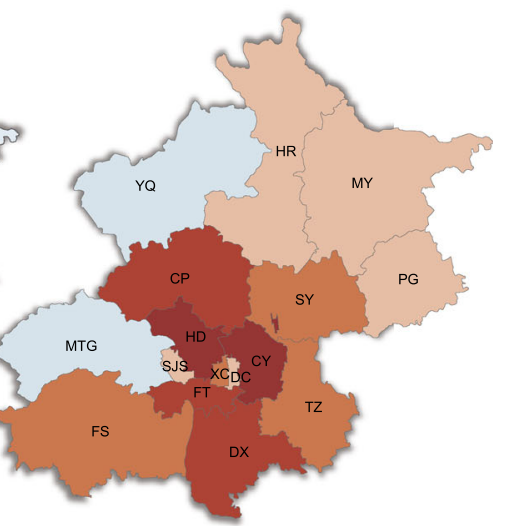

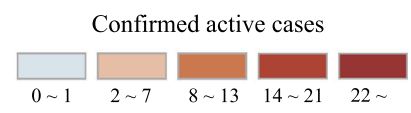

Fig. 4 Spatio-temporal prediction of the number of active cases in Beijing before and after resuming work. a-d active cases during resuming work at the $50 \%, 70 \%, 90 \%$ and $100 \%$ stages, respectively. $\mathbf{e}-\mathbf{g}$ active cases in the post-pandemic future with society in full operation 
for monitoring. Finally, all operations resumed by 10 April 2020, such that science/culture and education services, especially schools in Haidian District and Chaoyang District, should be included for close monitoring. In the postCOVID-19 future in Beijing, we find that the epidemic can be contained (see Fig. $4 \mathrm{e}-\mathrm{g}$ ) based on our simulation with existing epidemic-prevention measures published in Beijing. Figure $4 \mathrm{~g}$ illustrates that there are five districts with moderate risk, seven districts with mild risk and four districts with low risk on 30 May. Southern Beijing poses a higher risk than northern Beijing, because of a high density of SEAPs.

Reproductive number is an intrinsic property which characterizes the evolution of an epidemic. Table 3 shows that the reproductive number in each district was generally lower than 1 during the resumption of work, estimated by the district-specific transmission model for quarantine. Amongst the top 10 provinces and cities with the largest numbers of total confirmed cases, Beijing moved downward in the rank list quickly (Kraemer et al. 2020). However, the risk assessment provided by the revised SEIR model provides only an empirical estimate. The small reproductive numbers for all the districts of Beijing represent that the epidemic was dying at different stages of resuming work with the step-by-step return-to-work policy in Beijing. In fact, the deterministic reproductive number estimated by the pandemic data represents a similar risk pattern. The deterministic reproductive number decreases to null, because there is no evidence that the epidemic remains active in Beijing except through imported active cases. Besides, the deterministic and model-based reproductive numbers cannot be directly compared by the size of values. The minimum deterministic reproductive number is 1 if there are any new cases. In contrast, the model-based reproductive number can close to zero when there still are new cases. It should be noted that the model-based reproductive number tends to increase with progress towards resuming work because of the increasing contact number, but the reproductive numbers are all lower than 1 because of the quarantine, which means that the epidemic is still under control. Nevertheless, the model-based reproductive number varies in the districts of Beijing because of the heterogeneous medical capacity, although the cumulative number of cases in each district is almost static.

\section{Discussion and conclusion}

Faced with the COVID-19 outbreak, a variety of different stringent measures were taken in a short time by the Chinese government (Tian et al. 2020a, b; Ferretti et al. 2020). From 23 January, a total of 31 provinces implemented a public health level 1 response, shutting down businesses and industry, cancelling mass gatherings and restricting movement. Medical resources were also sent from other regions of China to support Wuhan. As the capital city of China, Beijing implemented even stricter measures than
Table 3 District-specific reproductive numbers at different stages of resuming work

\begin{tabular}{|c|c|c|c|c|c|c|c|c|c|c|c|c|}
\hline \multirow[t]{3}{*}{ District } & \multicolumn{12}{|c|}{ The reproductive number $\mathrm{R}$} \\
\hline & \multicolumn{6}{|c|}{ Deterministic } & \multicolumn{6}{|c|}{ Model-based } \\
\hline & $50 \%$ & $60 \%$ & $70 \%$ & $80 \%$ & $90 \%$ & $100 \%$ & $50 \%$ & $60 \%$ & $70 \%$ & $80 \%$ & $90 \%$ & $100 \%$ \\
\hline DC & 1.47 & 1 & 1 & Null & Null & Null & 0.28 & 0.29 & 0.29 & 0.36 & 0.36 & 0.40 \\
\hline $\mathrm{XC}$ & 1.77 & Null & Null & Null & Null & Null & 0.22 & 0.24 & 0.24 & 0.30 & 0.30 & 0.34 \\
\hline CY & 1.67 & 2.33 & Null & Null & Null & Null & 0.32 & 0.34 & 0.34 & 0.44 & 0.44 & 0.51 \\
\hline FT & 1.61 & 1.36 & Null & Null & Null & Null & 0.24 & 0.26 & 0.26 & 0.33 & 0.33 & 0.37 \\
\hline SJS & 1.43 & Null & Null & Null & Null & Null & 0.22 & 0.23 & 0.23 & 0.29 & 0.29 & 0.34 \\
\hline HD & 1.68 & 1 & Null & 1 & Null & Null & 0.27 & 0.28 & 0.28 & 0.35 & 0.35 & 0.43 \\
\hline MTG & 1.17 & Null & Null & Null & Null & Null & 0.02 & 0.03 & 0.03 & 0.03 & 0.03 & 0.04 \\
\hline FS & 1.44 & Null & Null & Null & Null & Null & 0.04 & 0.04 & 0.04 & 0.06 & 0.06 & 0.07 \\
\hline $\mathrm{TZ}$ & 1.47 & Null & Null & Null & Null & Null & 0.16 & 0.17 & 0.17 & 0.21 & 0.21 & 0.24 \\
\hline SY & 1.37 & Null & Null & Null & Null & Null & 0.10 & 0.10 & 0.10 & 0.13 & 0.13 & 0.15 \\
\hline $\mathrm{CP}$ & 1.54 & Null & Null & Null & Null & Null & 0.09 & 0.10 & 0.10 & 0.14 & 0.14 & 0.17 \\
\hline DX & 1.58 & Null & Null & Null & Null & Null & 0.16 & 0.17 & 0.17 & 0.21 & 0.21 & 0.23 \\
\hline HR & 1.31 & Null & Null & Null & Null & Null & 0.03 & 0.03 & 0.03 & 0.04 & 0.04 & 0.04 \\
\hline PG & Null & Null & Null & Null & Null & Null & 0.20 & 0.22 & 0.22 & 0.25 & 0.25 & 0.30 \\
\hline MY & 1.31 & Null & Null & Null & Null & Null & 0.02 & 0.02 & 0.02 & 0.02 & 0.03 & 0.03 \\
\hline YQ & 1 & Null & Null & Null & Null & Null & 0.01 & 0.01 & 0.01 & 0.01 & 0.02 & 0.02 \\
\hline
\end{tabular}

The deterministic $\mathrm{R}$ is null means there is no case identified during the related period 
other provinces, which were successful in preventing and controlling the COVID-19 infection.

Overall, the model-based reproductive number suggests that the quarantine and social distancing measures were effective in curbing the epidemic, while the deterministic reproductive number indicates that the epidemic is not yet dismissed in Beijing and areas with lesser medical capacity should be monitored particularly closely. To support economic recovery while minimizing disease-related risk from the outbreak, stringent measures should be taken by local governments in different regions. Regions with high density public transportation services are suggested to strengthen public guidance, control the number of people entering stations, increase the use of temperature detection devices in stations and clean train and bus carriages before each trip. Regions with densely distributed indoor public places, such as hotels and restaurants, should pay special attention to air circulation, and surface cleaning and disinfection. In enterprises and Commercial Business, monitoring of individuals' temperatures, strict control of the numbers of workers in confined spaces and installation of windows that can be opened for regular ventilation is encouraged (Wu et al. 2020; Hellewell et al. 2020).

While there has been encouraging news that no new infections inside China are being reported, other parts of the world are becoming the new epicenters of the outbreak. Clearly, China is at a different stage in the COVID-19 pandemic cycle than many other major economies. At this time, the world's mega-cities such as New York, Paris and London are coping with the impacts of the first wave of the pandemic. The experience of Beijing should be of great significance to other countries where the pandemic curve is still rising, especially developing regions with poor health services (Simon et al. 2005).

Efforts towards economic recovery will be required for all the cities suffering from the pandemic, especially megacities with dense industrial and populated areas. Evidence from Beijing shows that step-by-step measures can support economic recovery while avoiding a second pandemic outbreak. Beijing started resuming work on 10 February, when the number of infected cases was still rising, so only some major projects were resumed at that time. About ten days later, by February 19, some $61 \%$ of companies and industries resumed work, as the number of confirmed cases in Beijing reached 400 and stabilized. Meanwhile, some markets and shops reopened, to meet the basic requirements of daily life for people in Beijing. By 15 March, about $89 \%$ of companies and industries resumed work. Thus, the rate of resuming work in Beijing was about $10 \%$ every ten days. The model simulation undertaken here demonstrates that this pace of resuming work can be relatively effective, allowing control of the number of infections while restarting the economy as soon as possible. We hope that cities in other countries find this research useful in implementing their own policies to resume economic activity in the future.

Funding The national natural science foundation for distinguished young scholars of China (No. 41725006).

\section{Appendix}

\section{Spatial heterogeneity of the involved multi- source data}

The residents of Beijing are distributed unevenly with respect to its districts. The majority of residents live in southern Beijing, especially in Haidian District and Chaoyang District. In-migrants are distributed in a similar, but more centralized, pattern, reflecting the distribution of workplaces and infrastructure. Medical services are highly centralized in the center of Beijing (i.e. in Dongcheng District and Xicheng District).

Workplace distribution was based on the density and distribution of the 10 categories of POIs: Food \& Beverages, Enterprises, Finance \& Insurance Service, Commercial House, Governmental Organization \& Social Group, Shopping, Transportation Service, Science/Culture \& Education Service, Sports \& Recreation and Accommodation Service. In general, social-economic factors are concentrated in Dongcheng District and Xicheng District, as well as in the adjacent Chaoyang District, Haidian District, Fengtai District and Shijingshan District. Highdensity POI areas are also found in some towns in Daxing District, Tongzhou District, Changping District and Shijingshan District. There are also scattered high-density areas in a few towns in the east of Fangshan District, the central part of Changping District, the central part of Shunyi District, around Pinggu Town in Pinggu District, along Gulou Street in Miyun District and along Quanhe Street in Huairou District.

Overall, Dongcheng District, Xicheng District, the west of Chaoyang District and the southeast of Haidian District are the highest-density areas of multi-source data. POI in the Science/Culture \& Education Service category are more concentrated in the southeast of Haidian District; POIs from the Finance \& Insurance Service category are relatively rare in Haidian District; and the distribution of POIs in the Accommodation Service category are more centrally concentrated (Table 4, Figs. 5, 6).

Different major categories of POI reopened in turn amid business resumption in Beijing, i.e. with different stages of resumption rate, there will be different major categories of POI exist. The spatial patterns of the densities of different 


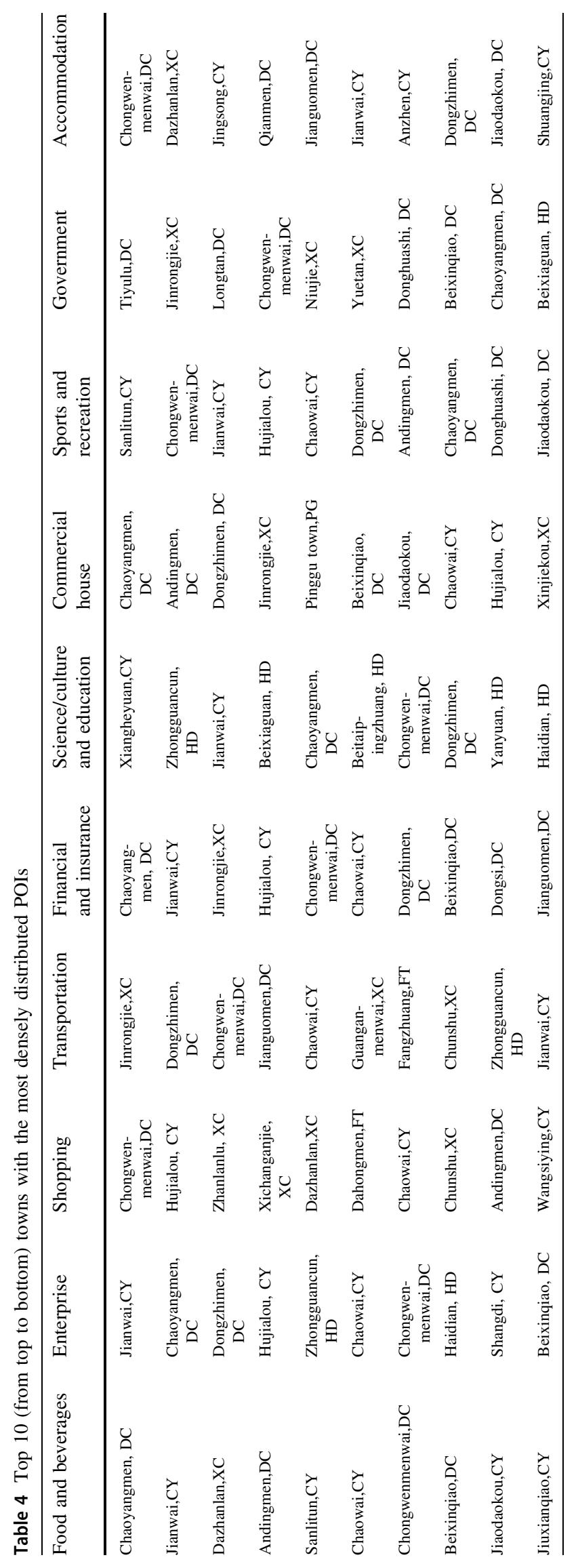



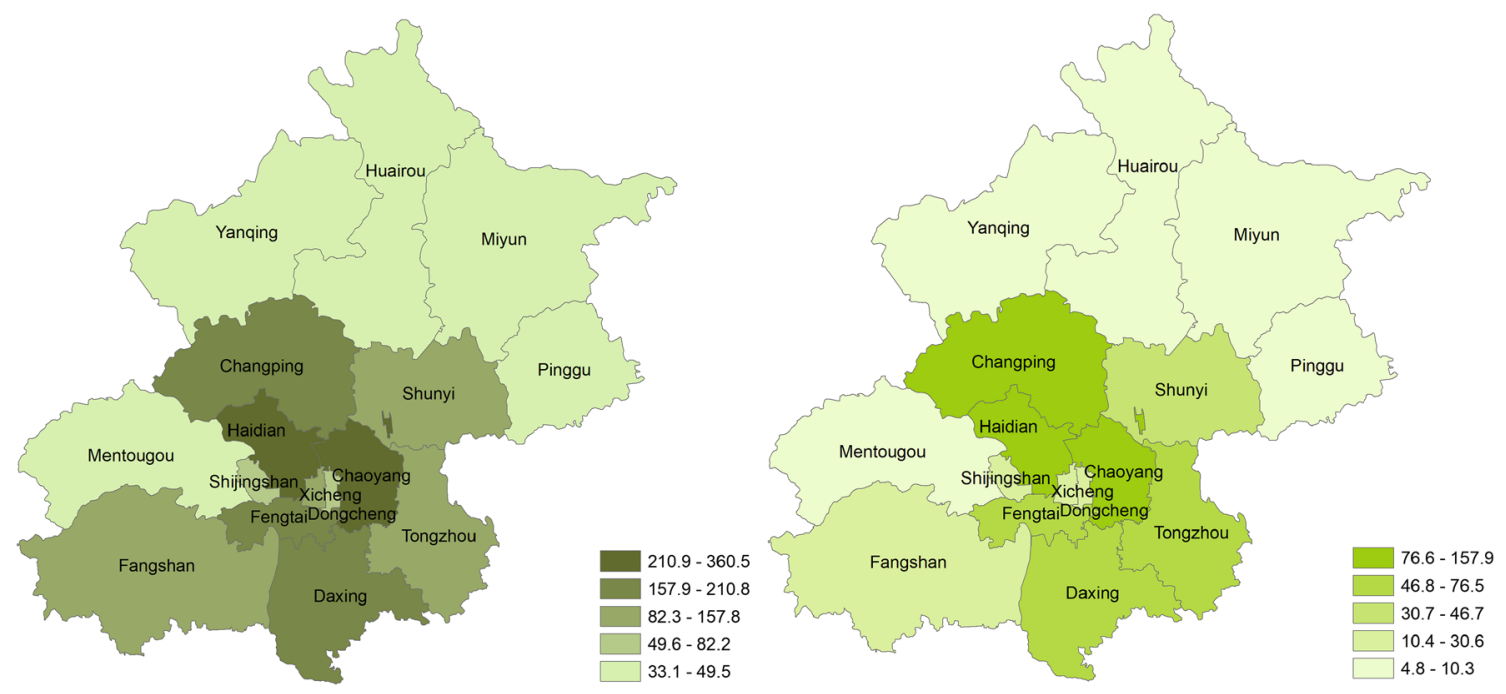

Fig. 5 The spatial distribution of (left) local residents and (right) migration in Beijing

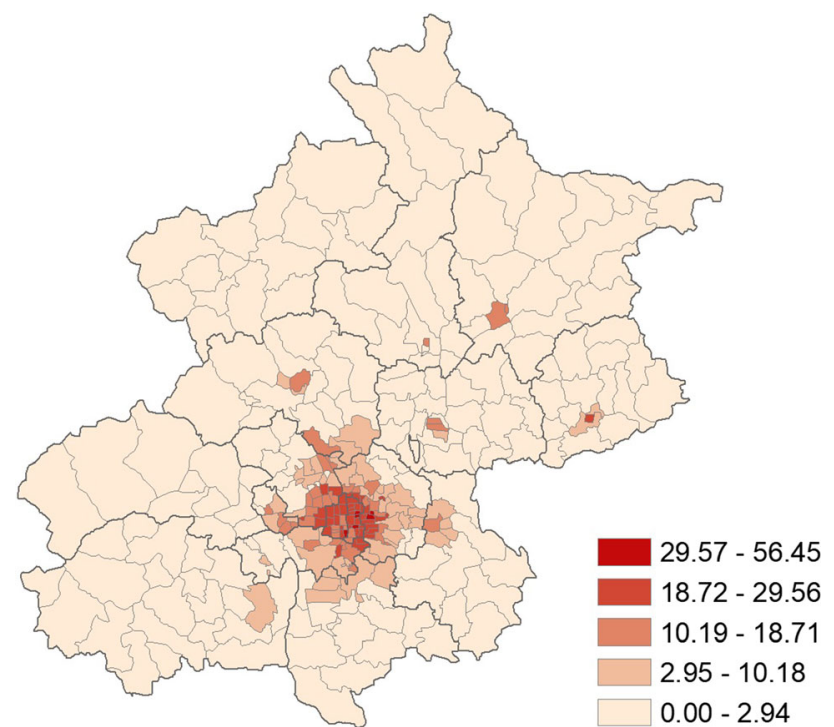

Fig. 6 The spatial distribution of the density of medical services in Beijing

major categories of POI are shown in Fig. A3. With respect to a specific major category POI, despite the ability of attracting people for each single POI is the same, the densities of this major category POI within all districts are different leading to a different overall ability of attracting people. Therefore, the POI determined parameters $k$ and $w$ are different for each district. On the other hand, for a specific district, the parameter $k$ varies with the resumption rate. In this study, we simply assume that only the major categories vary with different resumption rates. That is, we only consider the existence of each major category of the POI data instead of the resumption extent of each major category for every resumption rate. When resuming work of $50 \%$ in the early stages, there are five major categories of POI reopen, and they are Commercial House, Governmental Organization \& Social Group, Finance \& Insurance Service, Enterprises, and Accommodation Service. When resuming work of $60 \%$, the only difference is there will be another new major category exist and contribute to the calculation of corresponding parameters, i.e. Shopping. Then, POIs in Food \& Beverages and Transportation Service continues to reopen when resuming work of $80 \%$ and $90 \%$, respectively. In the last stage, i.e., the stage of resumption rate of $100 \%$, POIs in the Science/Culture \& Education Service and Sports \& Recreation categories reopen eventually. Therefore, the legend indicates the opened major categories for each resumption rate. Besides, the reopened major categories of a smaller resumption rate will also be opened at a bigger resumption rate. Thus, we use different colors to represent the added new major categories for every resumption rate (Fig. 7).

The contact number $k$ is evaluated based on 10 top-level categories with 60 middle-level categories. The detection rate $w$ is evaluated based on 1 top-level category with 4 middle-level categories, respectively. For each top-level category, its density is determined by the integrated density of corresponding mid categories with preset weights. Then, the parameter is evaluated by the integrated density of big categories in the same way. Besides, under each scenario of resuming work, the big categories contribute to the contact number $k$ are dynamic (Tables 5, 6, Fig. 8).

Fig. 7 The spatial distribution of POI density, which can reflect social activity strength. a Commercial House. b Government Organization \& Social Group. c Finance \& Insurance Service. d Enterprises. e Accommodation Service. f Shopping. g Food \& Beverages. h Transportation Service. i Science/Culture \& Education Service. j Sports \& Recreation 


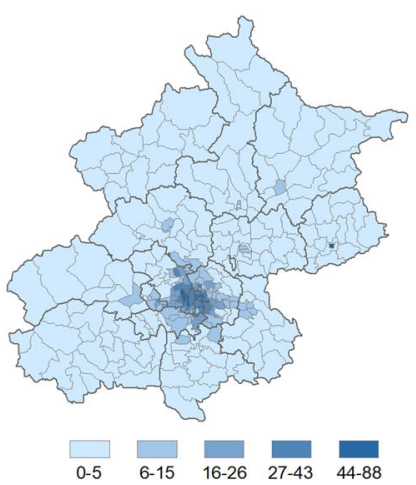

(a) Commercial House

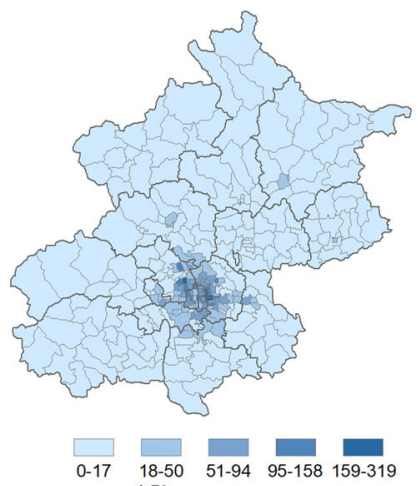

(d) Enterprises

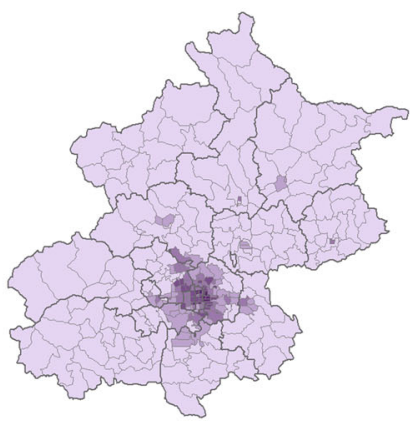

$\begin{array}{lllll}0-16 & 17-47 & 48-82 & 83-131 & 132-214\end{array}$

(g) Food \& Beverages

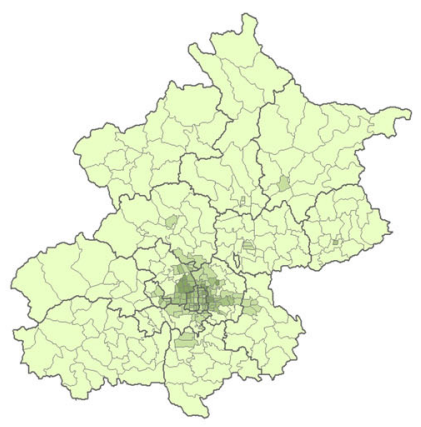

$\begin{array}{lllll}\square-12 & \square 3-36 & 37-70 & 71-135 & 136-239\end{array}$

(i) Science/Culture \& Education Service

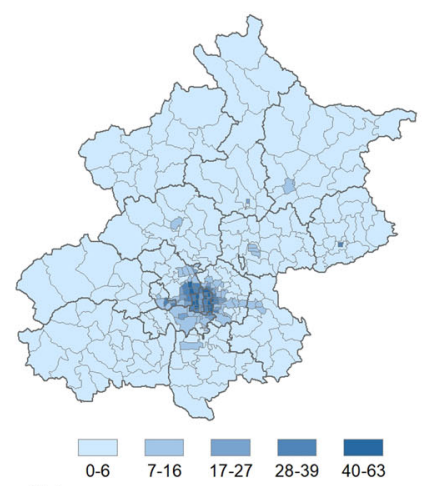

(b) Governmental Organization \& Social Group

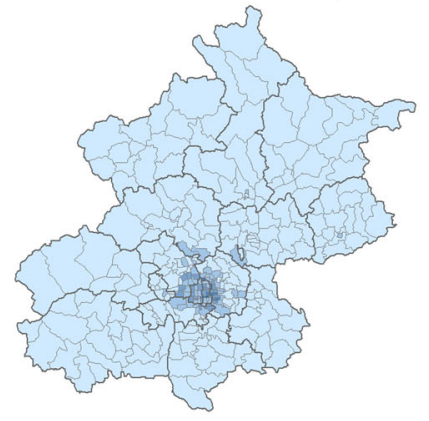

$\begin{array}{lllll}\square-5 & 6-15 & 16-30 & & \\ 31-72 & 73-189\end{array}$

(e) Accommodation Service

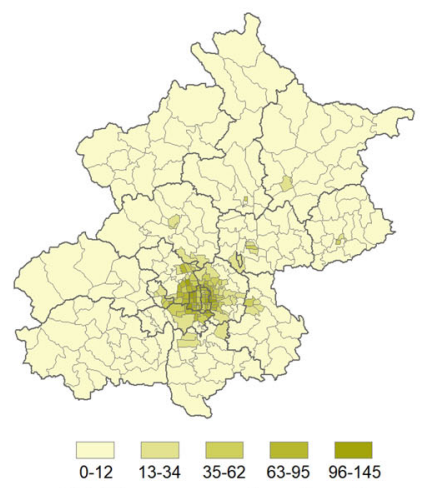

(h) Transportation Service

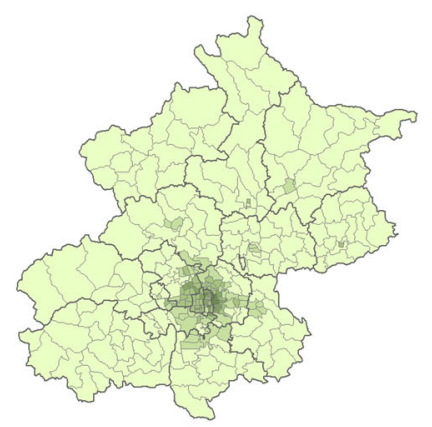

$\begin{array}{lllll}\square-5 & 6-14 & 15-25 & 26-43 & 44-67\end{array}$

(j) Sports \& Recreation

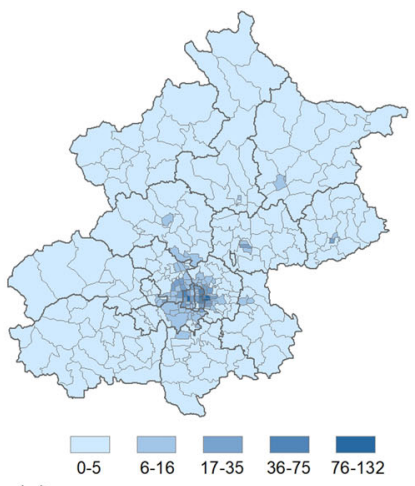

(c) Finance \& Insurance Service

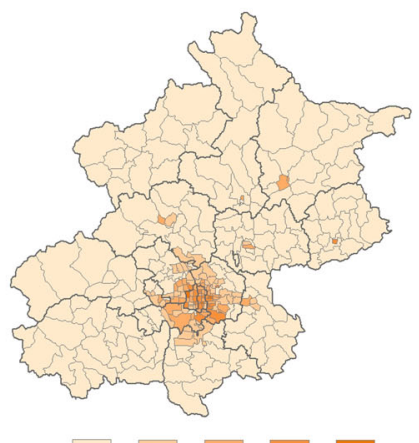

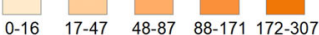

(f) Shopping
Legend of POI when resuming work of $50 \%$

Spatial distribution of added $\mathrm{POI}$ when resuming work of $60 \%$

Spatial distribution of added POI when resuming work of $80 \%$

$\square \square \square \square \square$ Spatial distribution

of added $\mathrm{POI}$ when resuming work of $90 \%$

$\square \square \square$ Spatial distribution of added POI when resuming work of $100 \%$ 
Table 5 The weight for each mid categories and big categories respectively

\begin{tabular}{|c|c|c|c|}
\hline Big category & Weight & Mid category & Weight \\
\hline \multirow[t]{9}{*}{ Food \& Beverages } & \multirow[t]{9}{*}{$0-1$} & Chinese Food Restaurant & $0-2$ \\
\hline & & Foreign Food Restaurant & $0-1$ \\
\hline & & Fast Food Restaurant & $0-1$ \\
\hline & & Leisure Food Restaurant & $0-1$ \\
\hline & & Coffee House & $0-1$ \\
\hline & & Tea House & $0-1$ \\
\hline & & Icecream Shop & $0-1$ \\
\hline & & Bakery & $0-1$ \\
\hline & & Dessert House & $0-1$ \\
\hline \multirow[t]{14}{*}{ Shopping } & \multirow[t]{14}{*}{$0-05$} & Shopping Plaza & $0-15$ \\
\hline & & Convenience Store & $0-05$ \\
\hline & & Home Electronics Hypermarket & $0-05$ \\
\hline & & Supermarket & $0-05$ \\
\hline & & Plants \& Pet Market & $0-05$ \\
\hline & & Home Building Materials Market & $0-05$ \\
\hline & & Comprehensive Market & $0-15$ \\
\hline & & Stationary Store & $0-05$ \\
\hline & & Sports Store & $0-05$ \\
\hline & & Commercial Street & $0-15$ \\
\hline & & Clothing Store & $0-05$ \\
\hline & & Franchise Store & $0-05$ \\
\hline & & Special Trade House & $0-05$ \\
\hline & & Personal Care Items Shop & $0-05$ \\
\hline \multirow[t]{6}{*}{ Sports \& Recreation } & \multirow[t]{6}{*}{$0-05$} & Sports Stadium & $0-3$ \\
\hline & & Golf Related & $0-1$ \\
\hline & & Recreation Center & $0-3$ \\
\hline & & Holiday \& Nursing Resort & $0-05$ \\
\hline & & Recreation Place & $0-15$ \\
\hline & & Theatre \& Cinema & $0-1$ \\
\hline \multirow[t]{2}{*}{ Accommodation Service } & \multirow[t]{2}{*}{0.1} & Hotel & $0-4$ \\
\hline & & Hostel & $0-6$ \\
\hline \multirow[t]{3}{*}{ Commercial Business } & \multirow[t]{3}{*}{$0-1$} & Industrial Park & $0-4$ \\
\hline & & Building & $0-5$ \\
\hline & & Residential Area & $0-1$ \\
\hline \multirow[t]{4}{*}{ Governmental Organization } & \multirow[t]{4}{*}{$0-13$} & Social Groups & $0-2$ \\
\hline & & Governmental Organization & $0-5$ \\
\hline & & Foreign Organization & $0-1$ \\
\hline & & Democratic Party & $0-2$ \\
\hline \multirow[t]{4}{*}{ Science/Culture \& Education Service } & \multirow[t]{4}{*}{$0-14$} & School & $0-5$ \\
\hline & & Research Institution & $0-1$ \\
\hline & & Training Institution & $0-3$ \\
\hline & & Driving School & $0-1$ \\
\hline \multirow[t]{6}{*}{ Transportation Service } & \multirow[t]{6}{*}{$0-17$} & Airport Related & $0-2$ \\
\hline & & Railway Station & $0-2$ \\
\hline & & Coach Station & $0-2$ \\
\hline & & Subway Station & $0-1$ \\
\hline & & Light Rail Station & $0-1$ \\
\hline & & Bus Station & $0-1$ \\
\hline
\end{tabular}


Table 5 (continued)

\begin{tabular}{|c|c|c|c|}
\hline Big category & Weight & Mid category & Weight \\
\hline & & Commuter Bus Station & $0-1$ \\
\hline \multirow[t]{6}{*}{ Finance \& Insurance Service } & $0-03$ & Finance \& Insurance Service Institution & $0-15$ \\
\hline & & Bank & $0-15$ \\
\hline & & ATM & $0-1$ \\
\hline & & Insurance Company & $0-2$ \\
\hline & & Securities Company & $0-2$ \\
\hline & & Finance Company & $0-2$ \\
\hline \multirow[t]{5}{*}{ Enterprises } & $0-13$ & Enterprises & $0-1$ \\
\hline & & Famous Enterprise & $0-3$ \\
\hline & & Farming,Forestry,Animal Husbandry and Fishery Base & $0-1$ \\
\hline & & Company & $0-4$ \\
\hline & & Factory & $0-1$ \\
\hline \multirow[t]{4}{*}{ Medical Service } & $1^{*}$ & Hospital & $0-3$ \\
\hline & & Special Hospital & $0-4$ \\
\hline & & Clinic & $0-2$ \\
\hline & & Emergency Center & $0-1$ \\
\hline
\end{tabular}

*Note that only one category contributes to the parameter $w$, thus the weight is 1

Table 6 The top-level categories contributing to the contact number of each district at different stages of resuming work

\begin{tabular}{|c|c|c|c|c|c|c|c|}
\hline \multirow[t]{2}{*}{ Big category } & \multicolumn{7}{|c|}{ The level of resuming work $(\%)$} \\
\hline & baseline & 50 & 60 & 70 & 80 & 90 & 100 \\
\hline Food \& Beverages & & & & & $\sqrt{ }$ & $\sqrt{ }$ & $\sqrt{ }$ \\
\hline Shopping & & & $\sqrt{ }$ & $\sqrt{ }$ & $\sqrt{ }$ & $\sqrt{ }$ & $\sqrt{ }$ \\
\hline Sports \& Recreation & & & & & & & $\sqrt{ }$ \\
\hline Accommodation Service & $\sqrt{ }$ & $\sqrt{ }$ & $\sqrt{ }$ & $\sqrt{ }$ & $\sqrt{ }$ & $\sqrt{ }$ & $\sqrt{ }$ \\
\hline Commercial House & $\sqrt{ }$ & $\sqrt{ }$ & $\sqrt{ }$ & $\sqrt{ }$ & $\sqrt{ }$ & $\sqrt{ }$ & $\sqrt{ }$ \\
\hline $\begin{array}{l}\text { Governmental Organization \& Social Group } \\
\text { Science/Culture \& Education Service }\end{array}$ & $\sqrt{ }$ & $\sqrt{ }$ & $\sqrt{ }$ & $\sqrt{ }$ & $\sqrt{ }$ & $\sqrt{ }$ & $\begin{array}{l}\sqrt{ } \\
\sqrt{ }\end{array}$ \\
\hline Transportation Service & & & & & & $\sqrt{ }$ & $\sqrt{ }$ \\
\hline Finance \& Insurance Service & & $\sqrt{ }$ & $\sqrt{ }$ & $\sqrt{ }$ & $\sqrt{ }$ & $\sqrt{ }$ & $\sqrt{ }$ \\
\hline Enterprises & & $\sqrt{ }$ & $\sqrt{ }$ & $\sqrt{ }$ & $\sqrt{ }$ & $\sqrt{ }$ & $\sqrt{ }$ \\
\hline
\end{tabular}




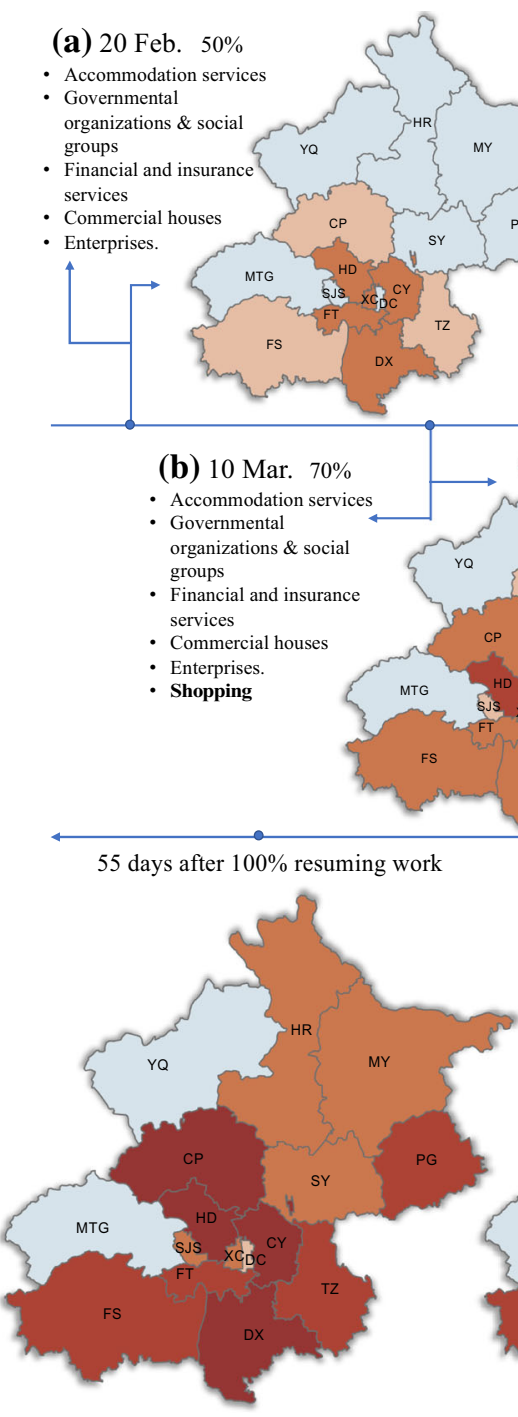

(g) 30 May (c) 30 Mar. $90 \%$ - Accommodation services - Governmental

organizations \& social organiza
groups

- Financial and insurance services

- Commercial houses

- Enterprises.

- Shopping

- Food and beverages

- Transportation servies

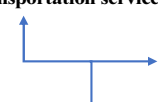

(d) 10 Apr. $100 \%$

- Accommodation services

- Governmental

organizations \& social

groups

- Financial and insurance

- Tervices

- Commercial houses

- Enterprises

- Food and beverages

- Transportation servi

- Science/culture \&

education services - Sports \& recreation

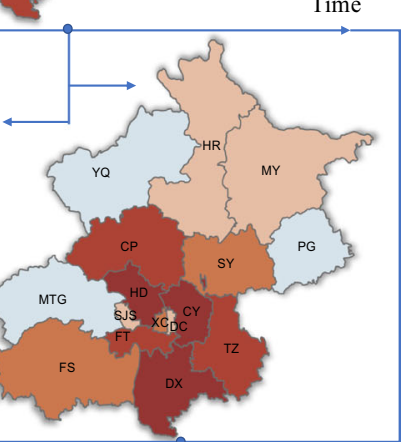

35 days after $100 \%$ resuming work

10 days after $100 \%$ resuming work

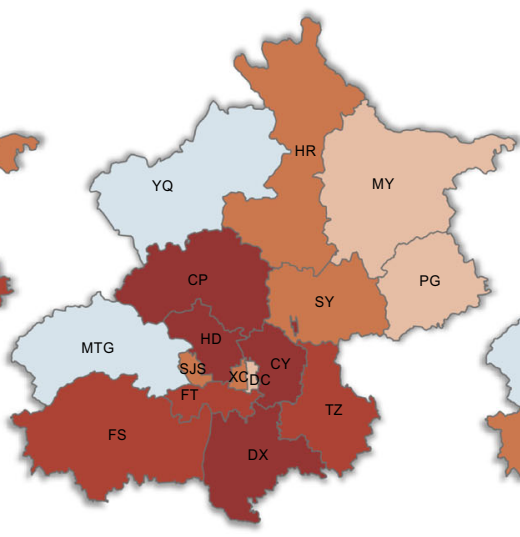

(f) 15 May

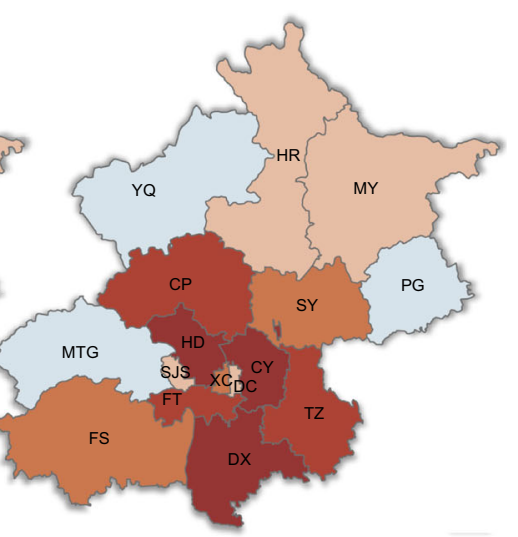

(e) 20 Apr.

Total confirmed cases

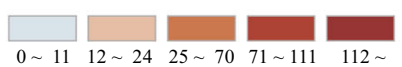

Fig. 8 The estimated total confirmed cases in Beijing under resuming work. a-d The total number of confirmed cases in each district with resuming work at $50 \%, 70 \%, 90 \%$ and $100 \%$, respectively. e-g The

\section{References}

Amorós R, Conesa D, López-Quílez A et al (2020) A spatio-temporal hierarchical Markov switching model for the early detection of influenza outbreaks. Stoch Environ Res Risk Assess 34:1-18

Anderson RM, May RM (1991) Infectious diseases of humans: dynamics and control. Oxford University Press, Oxford

Aschwanden C (2004) Spatial simulation model for infectious viral diseases with focus on SARS and the common flu. In: 37th annual hawaii international conference on system sciences, USA

Bai Y, Yao L, Wei T et al (2020) Presumed asymptomatic carrier transmission of COVID-19. JAMA. https://doi.org/10.1001/ jama.2020.2565pmid:32083643 total number of confirmed cases in each district in the post-COVID19 future with society in full operation

Beijing Municipal Bureau Statistics (2019) Beijing Statistical Yearbook in 2019. China Statistics Press, Beijing

Beijing Youth Daily (2020) Workers have returned to work one by one, while work resumed step by step

Brunton LA, Alexander N, Wint W et al (2017) Using geographically weighted regression to explore the spatially heterogeneous spread of bovine tuberculosis in England and Wales. Stoch Environ Res Risk Assess 31:339-352

Cai J, Sun W, Huang J, Gamber M, Wu J, He G (2020) Indirect virus transmission in cluster of COVID-19 cases, Wenzhou, China, 2020. Emerg Infect Dis 26:6

Chen S, Yang J, Yang W, Wang C, Bärnighausen T (2020) COVID19 control in China during mass population movements at New Year. Lancet 395:764-766 
Chien L, Chen L (2020) Meteorological impacts on the incidence of COVID-19 in the U.S. Stoch Environ Res Risk Assess. https:// doi.org/10.1007/s00477-020-01835-8

Chinazzi M, Davis JT, Ajelli M et al (2020) The effect of travel restrictions on the spread of the 2019 novel coronavirus (COVID-19) outbreak. Science. https://doi.org/10.1126/science. aba9757

Choi K, Yu H, Wilson ML (2008) Spatiotemporal statistical analysis of influenza mortality risk in the State of California during the period 1997-2001. Stoch Environ Res Risk Assess 22:15-25

Christakos G, Zhang C, He J (2017) A traveling epidemic model of space-time disease spread. Stoch Environ Res Risk Assess 31:305-314

Dorigatti I, Okell L, Cori A, et al (2020) Report 4: Severity of 2019-novel coronavirus (nCoV). www.imperial.ac.uk/media/imperial-college/medicine/sph/ide/gida-fellowships/Imperial-College-COVID19-severity-10-02-2020.pdf. Accessed 10 February 2020

Enserink M, Kupferschmidt K (2020) With COVID-19, modeling takes on life and death importance. Science 367:1414-1415

European Centre for Disease Prevention and Control (2020) Situation update worldwide. https://www.ecdc.europa.eu/en/covid-19pandemic

Ferretti L, Wymant C, Kendall M et al (2020) Quantifying SARS$\mathrm{CoV}-2$ transmission suggests pandemic control with digital contact tracing. Science. https://doi.org/10.1126/science. abb6936

Hellewell J, Abbott S, Gimma A et al (2020) Feasibility of controlling COVID-19 outbreaks by isolation of cases and contacts. Lancet Glob Health 8:e488-e496

He S, Peng Y, Sun K (2020a) SEIR modeling of the COVID-19 and its dynamics. Nonlinear Dyn 101:1667-1680

He J, Chen G, Jiang Y, et al (2020b) Comparative analysis of COVID-19 transmission patterns in three Chinese Regions vs. South Korea, Italy and Iran. Preprint at medRxiv. https://doi.org/ 10.1101/2020.04.09.20053223

Hou C, Chen J, Zhou Y et al (2020) The effectiveness of quarantine of Wuhan city against the Corona Virus Disease 2019 (COVID-19): a well-mixed SEIR model analysis. J Med Virol 92:841-848

Kraemer MU, Yang CH, Gutierrez B et al (2020) The effect of human mobility and control measures on the COVID-19 pandemic in China. Science. https://doi.org/10.1126/science.abb4218

Lipsitch M, Cohen T, Cooper B et al (2003) Transmission dynamics and control of severe acute respiratory syndrome. Science 300:1966-1970

Langousis A, Carsteanu AA (2020) Undersampling in action and at scale: application to the COVID-19 pandemic. Stoch Environ Res Risk Assess 34:1281-1283

Lauer SA, Grantz KH, Bi Q, et al (2020) The incubation period of 2019-nCoV from publicly reported confirmed cases: Estimation and application. medRxiv. https://doi.org/10.1101/2020.02.02. 20020016

Li Q, Guan X, Wu P et al (2020) Early transmission dynamics in Wuhan, China, of novel coronavirus-infected pneumonia. N Engl J Med 382:1199-1207

Lopez LR, Rodó X (2020) A modified SEIR model to predict the COVID-19 outbreak in Spain and Italy: simulating control scenarios and multi-scale epidemics. Preprint at medRxiv. https://doi.org/10.1101/2020.03.27.20045005

Mizumoto K, Kagaya K, Zarebski A, Chowell G (2020) Estimating the asymptomatic ratio of 2019 novel coronavirus onboard the princess cruises ship. medRxiv. https://doi.org/10.1101/2020.02. 02.20020016

Moss R, Naghizade E, Tomko M, Geard N (2019) What can urban mobility data reveal about the spatial distribution of infection in a single city? BMC Public Health 19:656
Moustakas A (2017) Spatio-temporal data mining in ecological and veterinary epidemiology. Stoch Environ Res Risk Assess 31:829-834

Nishiura H, Linton N M, Akhmetzhanov A R (2020) Serial interval of novel coronavirus (2019-nCoV) infections. medRxiv. https://doi. org/10.1101/2020.02.03.20019497

North China Morning Post (2020) Coronavirus: the new disease Covid-19 explained. https://multimedia.scmp.com/infographics/ news/china/article/3047038/wuhan-virus/index.html?src=articlelauncher. Accessed 21 January 2020

Qian H, Li Y, Nielsen PV et al (2009) Spatial distribution of infection risk of SARS transmission in a hospital ward. Build Environ 44:1651-1658

Rothe C, Schunk M, Sothmann P et al (2020) Transmission of 2019-nCoV infection from an asymptomatic contact in Germany. N Engl J Med 382:970-971

Simon IH, Guerra Carlos A, Tatem Andrew J et al (2005) Urbanization, malaria transmission and disease burden in Africa. Nat Rev Microbiol 3:81-90

Sivakumar B (2020) COVID-19 and water. Stoch Environ Res Risk Assess. https://doi.org/10.1007/s00477-020-01837-6

Song C, He Y, Bo Y et al (2019) Disease relative risk downscaling model to localize spatial epidemiologic indicators for mapping hand, foot, and mouth disease over China. Stoch Environ Res Risk Assess 33:1815-1833

Sujath R, Chatterjee JM, Hassanien AE (2020) A machine learning forecasting model for COVID-19 pandemic in India. Stoch Environ Res Risk Assess 34:959-972

Tian H, Liu Y, Li Y et al (2020a) An investigation of transmission control measures during the first 50 days of the COVID-19 pandemic in China. Science. https://doi.org/10.1126/science. abb6105

Tian S, Hu N, Lou J et al (2020b) Characteristics of COVID-19 infection in Beijing. J Infection 80(4):401-406

Tong Z-D, Tang A, Li K-F et al (2020) Potential presymptomatic transmission of SARS-CoV-2, Zhejiang Province, China, 2020. Emerg Infect Dis 26:5

World Health Organization (2020a) Novel Coronavirus - Situation Report 50. https://www.who.int/docs/default-source/coronaviruse/situation-reports/20200310-sitrep-50-covid19.pdf?sfvrsn $=55 \mathrm{e} 904 \mathrm{fb} \_2$ Accessed 10 March 2020

World Health Organization (2020b) Naming the coronavirus disease (COVID-19) and the virus that causes it https://www.who.int/ emergencies/diseases/novel-coronavirus-2019/technical-guidance/naming-the-coronavirus-disease-(covid-2019)-and-thevirus-that-causes-it Accessed 10 March 2020

World Health Organization (2020c) Statement on the meeting of the International Health Regulations (2005) Emergency Committee regarding the outbreak of novel coronavirus (2019nCoV).https://www.who.int/news-room/detail/23-01-2020-statement-on-the-meeting-of-the-international-health-regulations(2005)-emergency-committee-regarding-the-outbreak-of-novelcoronavirus-(2019-ncov) Accessed 23 January 2020

Wu JT, Leung K, Leung GM (2020) Nowcasting and forecasting the potential domestic and international spread of the 2019-nCoV outbreak originating in Wuhan, China: a modelling study. Lancet 395:689-697

Xia W, Sanyi T, Yong C et al (2020) When will be the resumption of work in Wuhan and its surrounding areas during COVID-19 pandemic? A data-driven network modeling analysis. Sci Sin Math 50:1-10

Xinhua net (2020a) Beijing resumed construction project safely and orderly. http://m.xinhuanet.com/bj/2020-02/10/ c_1125554153.htm. Accessed 10 February 2020

Xinhua net (2020b) The resumption rate of industrial enterprises above designated size in Beijing is close to $90 \%$ 
Wei Y, Lu Z, Du Z et al (2020) Fitting and forecasting the trend of COVID-19 by SEIR + CAQ dynamic model. Chin J Epidemiol 41:470-475

Yin Q, Wang JF, Ren ZP et al (2019) Mapping the increased minimum mortality temperatures in the context of global climate change. Nat Commun 10:4640

Yang Z, Zeng Z, Wang $\mathrm{K}$ et al (2020) Modified SEIR and AI prediction of the epidemics trend of COVID-19 in China under public health interventions. J Thorac Dis 12(3):165-174
Zhu N, Zhang D, Wang W et al (2020) China Novel Coronavirus Investigating and Research Team, A novel coronavirus from patients with pneumonia in China, 2019. N Engl J Med 382:727-733

Publisher's Note Springer Nature remains neutral with regard to jurisdictional claims in published maps and institutional affiliations. 